\title{
Strategic Human Resource Management And Global Expansion Lessons From The Euro Disney Challenges In France
}

Guergana Karadjova-Stoev, Nova Southeastern University, USA Bahaudin G. Mujtaba, Nova Southeastern University, USA

\begin{abstract}
The strategic role of human resource (HR) management should be seen as an integral element of a company's overall success in accomplishing its mission and business strategy. The paper will demonstrate how the decisions of a company's HR department are essential for a company's longterm success. In other words, strategic planning will not be presented solely as a company's objective, but a human resource imperative as demonstrated through the Euro Disney case. In the case of Euro Disney, strategic HR management was simply missing, which caused the company's initial strategy not to be successful in Europe. While analyzing the case and what the situation could have been with the exercise of HR's strategic role, emphasis is placed on the importance of cultural awareness. For the purpose of further clarifying the importance of cultural awareness, a comparison is drawn between the United States and France as some of the most important lessons both for Disney and other multinational enterprises are outlined.
\end{abstract}

\section{STRATEGIC HUMAN RESOURCE MANAGEMENT}

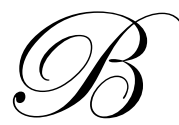

enjamin Franklin once said: "Well done is better than well said." By that, he was implying that words alone cannot achieve much. Rather, they should be supported by well thought actions. In the language of business this means that strategic planning allows companies to put down on paper where they are, where they want to go, and how they plan to get there. But the best planning in the world does nothing for a company if it does not act on those plans in an appropriate manner (OPM, 1999). In this aspect, strategic human resources management has been defined as 'the linking of human resources with strategic goals and objectives in order to improve business performance and develop an organizational culture that fosters innovation and flexibility' (Chaturvedi, 2006). Strategic HR means accepting the HR function as a strategic partner in the formulation of the company's strategies as well as in the implementation of those strategies through HR activities such as recruiting, selecting, training and rewarding personnel (Chaturvedi, 2006). In addition, among the other roles that a company's strategic HR management should be responsible for are (Chaturvedi, 2006):

- $\quad$ Environmental scanning, i.e. identifying and analyzing external opportunities and threats that may be crucial to the company's success.

- $\quad$ Supplying of competitive intelligence that may be useful in the long-term planning process.

- $\quad$ Supplying information regarding the company's strengths and weaknesses. The strengths and weaknesses of a company's human resources can have a determining effect on the viability of the firm's strategic options.

In the modern business world, rather than being supportive, HRM plays a strategic role by aiming at facilitating the accomplishment of a company's mission and ensuring a company's competitive advantage. The goal is to move a company's strategy to action and to design practices that align with the business strategy. By fulfilling this role, HR professionals increase the capacity of a business to execute its strategies and to execute it well. 
The role of strategic planning is to provide organizations and agencies with a clear sense of direction by clarifying their mission, priorities, and goals and objectives (Thompkins, 2002, p. 97). The goal of managers should be to link the strategic objectives to efficiently position the firm's human resources to accomplish the stated mission. Thompkins states that the performance management approach "aims to ensure accountability" (2002, p. 98). An example of this is the daily tracking of statistics that each employee turns in at the end of the month at some organizations or departments. The firm can use this information to follow the production of its employees and to see if they are actually working toward achieving the desired results. Thompkins states that employees "tend to skew goal statements, choice of performance measures, and actual behaviors towards those results that are easiest to achieve, whether or not they truly enhance organization performance" (2002, p. 100). Therefore, regularly monitoring performance to make sure the activities of employees and their results are linked to the strategies is a good initiative for management.

\section{Global Staffing Policies And Human Resource Orientations}

As part of their strategic management policies, global experts often follow one of the four different staffing orientations that human resource professionals can integrate into their day-to-day operations (Mujtaba, 2007a). As such, an understanding of ethnocentric, polycentric, regiocentric, and geocentric management orientations are a necessity for global management. Ethnocentric orientation is when the individual is home country centered. Polycentric orientation is when the individual is host country centered. Regiocentric is when the individual is focused on regional headquarters or regional basis. And in the geocentric orientation, the individual is world oriented.

In ethnocentric management orientation, the approach is basically "what works at home, will work here." One example of this is individuals who choose to open restaurants that are successful in the U.S., in a foreign country. Due to cultural differences, a company that mandates particular "work-shifts" may not be successful in Mexico or other Hispanic cultures with a polychronic time orientation where a linear view of time is not such a high priority. If a manager was successful with this approach in the U.S., and then began operations in Mexico, mandating employees to arrive at 7 a.m. may result in discharge or termination if the employee does not comply. The Mexican worker may arrive to work at eight or so, due to this polychronic view of time, and the company would not be successful. In fact, in this situation, the culture is this way and people are conditioned toward this orientation. Therefore, it would not be one individual who would arrive late; all employees of the culture may arrive early or a few minutes late. This would occur due to cultural differences conflicting with the ethnocentric orientation. The manager would be wise to reconsider the approach in this particular example.

In polycentric management orientation, managers believe the foreign market to be too difficult to understand. They remain host country centered. An example is Pepsi Cola. They operate in joint ventures in other countries. Basically, they bring individuals from other countries to the U.S., train them, and then allow them to work however they choose to accomplish the goals of the company. In this orientation, the company probably finds this approach easier and safer, but they fail to learn much about other cultures, or grow in their knowledge of world diversity.

In regiocentric management orientation, the company believes the regional managers are best able to organize operations within the region. Regional offices are at various locations, and report to a regional headquarters, and then to headquarters. An example may be an automobile manufacturer. Foreign automakers establish companies within the U.S., and they do not generally micromanage these foreign facilities, located in U.S. areas. They rely on the regional offices to monitor production of the cars, and then report back to headquarters.

In geocentric management orientation, the management style focuses on both local and worldwide objectives. The management style is interdependent. An example of such a company is Whirlpool; they were able to create a refrigerator from European insulation technology, U.S. manufacturing and design, and Brazilian affiliates. Therefore, in the geocentric management style, resources can come from virtually anywhere locally, or in the world.

Through these four types of management orientation, companies can clearly change from one orientation to another, depending on the needs of the company (Mujtaba, 2006). A company's main objective is to ensure success 
and survival of the organization. Therefore, a successful company would utilize whichever style of management orientation offered the greatest potential for success. Mujtaba (2007b) provides the following definitions and common knowledge for each orientation:

1. Ethnocentric management is where the home country management style is imposed on the host country. The assumption is that what works at home should also work overseas. This style of management is not well suited or applicable to the global world today. The management team has to diversify and adjust in being flexible to accommodate the host country's culture and employees' norms and social relation in the workplace.

2. In polycentric management, the foreign market is "too hard to understand," so host-country managers are relatively free to manage their own way. Competition is focused on a market-by-market basis. This type of management style is used by such franchises as McDonald's, Domino's Pizza, Kentucky Fried Chicken, Pizza Hut, and Burger King.

3. Regiocentric management is the style most parent organizations use when they feel that the regional insiders best coordinate operations within the region. The assumption is that the regional workers know their market better than others. Similarly, these employees can serve an entire region for economies of scale purposes instead of having many representatives in various countries.

4. Geocentric management is a highly interdependent system that speaks in terms of the global village. The focus is at once both worldwide and on local objectives. Some franchises operate based on the geocentric management orientation. They focus on being a worldwide business first and then they regionalize in groups.

One should remember that the four management orientations are not mutually exclusive. Therefore, they can all take place at one time within the same organization for its different departments or product lines. Many organizations often begin with the ethnocentric mindset or polycentric and gradually develop a more regiocentric or geocentric framework.

\section{Euro Disney And The Lack Of HR's Strategic Partnership}

As previously mentioned, strategic HR management is involved in determining the optimum site for a business and is responsible for many of the aspects considered in international expansion, such as cultural evaluation of the site, employee selection, training, development, compensation, and evaluation, just to name a few. Thus, the role of international HR management is to make a company's strategy happen by making sure that all of the business requirements of the host country are carefully analyzed and considered in the decision making process. As a result, the strategic role of a company's international HR department is to carefully research factors that might lead to a company's success or failure in a certain region and to make sure that it comprehends the laws, traditions, cultures, and people of a country in order for the problems that might occur to be minimized (Burgoyne, 1995).

In the case of Euro Disney, it is fair to say that initially Disney's HR department failed in almost all aspects considering the lack of cultural awareness, and misunderstanding of the French laws and the traditions/habits of the French people. Not surprisingly, Euro Disney can be used as an example of what a company's HR management should avoid doing and can be illustrative of the practices that should be considered in order for the strategic role of a company's HR management to be well performed and the company's strategy to be reached (Burgoyne, 1999).

In 1983, the Walt Disney Company opened in Tokyo, Japan, their first theme park outside the United States, Tokyo Disneyland, which became an instant hit. It was the success in Japan that made the Walt Disney Company's executives believe they learned so much about operating a theme park in another country, which motivated them to immediately start searching for a site for a fourth park. Thus, the Walt Disney Company targeted Europe, Paris for its fourth park. In 1992, the Walt Disney Company's fourth theme park, Euro Disneyland opened its doors to the public with essentially the same attractions as in the other Disney theme parks in California, Florida, and Japan (Price, 2000). Euro Disneyland's executives hoped to attract 11 million guests a year, more than twice the number of tourists that visit the Eiffel Tower. Euro Disneyland was confident that with its superior investment and professionalism it would succeed. If it did not, it would most likely be the fault of the weather and not of any French cultural traditions. Although Disney believed they had hit a "gold mine" by developing their fourth theme park just 
outside of Paris, they learned this was not the case. The dream of succeeding did not initially become a reality (Burgoyne, 1995).

One of the biggest mistakes that Disney did wrong in its planning for the Euro Disney was that the whole project was driven by the success that the three previous projects had experienced in Florida, California, and Japan. These three projects were almost identical, with Disney in Japan being a reflection of the American Disney. However, Disney's HR management did not consider something very important- cultural differences and the need of differentiation in the Euro Disney project, which should have been dictated by the recognition of diversity (Burgoyne, 1995).

Overall, the Walt Disney Company in general and the HR department in particular exercised ethnocentrism in the marketing approach by making no significant difference in the parks that were built in different countries. Here, it should be emphasized that such a behavior, despite being detrimental for Euro Disney's success, was not unusual for Walt Disney, which was an American based company. Although the American culture has always had an international flavor, a large number of Americans understand very little about the cultural values outside of their comfort zone. It is this sense of individualism in the American business culture that adversely affects quite often the decisions that are made when a company is operating in the global environment.

In relation to this ethnocentrism and universalistic approach in the launching of Euro Disney, the failure of Disney's HR management to assign responsibilities to the right employees must also be emphasized. American companies doing business globally often appoint home-country nationals at management level positions as the key players in the project implementation process. Euro Disney was promoted and defended by senior company managers in the United States, and as the chairman of Euro Disney was an appointed American who was argued to have strong ties with France. Blinded by their ethnocentric approach and beliefs that the success in Japan would be translated into France, Disney's HR management did not consider an extensive number of critical factors. In this aspect, they did not put too much of an emphasis to the fact that to be an American with strong ties in France did not mean that one has developed the French thinking, has become part of the French culture, and would incorporate French ideas in the project implementation. The lack of long-term strategic thinking and partnership factors turned out to be detrimental for Euro Disney's initial success (Keegan, 2002). After Walt Disney Company undertook an ethnocentric approach in assigning the most important position to an American and used universalistic approach in the creation of Euro Disney, without much consideration to local culture and traditions, Walt Disney was criticized for cultural imperialism. The company's attempt to be all things to all people led the initial Euro Disney project to failure (Price, 2000).

Perhaps Euro Disney's management also failed to recognize local employees for their contributions or to even seek their contributions in the initial planning process. Of course, the reality is that recognizing quality work performance goes a long way in the area of employee belongingness and overall departmental morale. When management expresses their gratitude for the work of their employees by verbal means or tangible rewards, it goes a long way toward reinforcing good behavior and deterring activities that are not aligned with the strategies of the department or organization. Possessing the ability to involve employees in the planning process as well as to recognize and reward employee contributions are vital in performance management and the success of the firm. Dolezalek (2008) illustrates that "something significant has to be accomplished so the recognition clearly was earned and not just given" (p. 34). It is important to involve and reward employees appropriately so that they can enhance the firm's overall success. When employees are ignored, the long-term success of the organization is doubtful.

Up until now, it has been discussed how the ethnocentric approach of Disney's HR management led to the wrong selection of the chairman for Euro Disney who was the key figure in managing the project in a way that the company's strategy failed. In the next few pages, in more detail, the failure of Disney's HR management to understand the French culture, the habits of the local people, the local laws and risks are discussed. An emphasis is placed in particular to those factors which demonstrate the magnitude of the problem. 


\section{Euro Disney: A Puzzle Of Errors- The Consequence Of HR's Ignorance}

It was mentioned a couple of times, that nowadays, a company's HR management does not have just a supportive role but a strategic one. It needs to align with the company's strategy, and by using its expertise, to play the role of a strategic partner who drives the realization of this strategy. As a result, a company's HR department must comprehend the laws, the possibility of possible risks, the traditions, the culture, and the people of a country in order to minimize problems which can occur. As was already mentioned, Disney's HR management failed in terms of assigning the right personnel at the beginning and now the errors of their lack of strategic thinking will demonstrate the rest of the complications presented in the next few pages:

Miscalculation of drinking habits. When Euro Disney started operations alcohol was not served. The source of the problem was that Walt Disney Company's policy of serving no alcohol in its parks in California, Florida, and Tokyo was extended to France. This caused astonishment and rebellion in France where a glass of wine for lunch is often a given. Not surprisingly, later on, the Walt Disney Company changed its policy and allowed wine and beer in the Euro Disneyland theme park (Burgoyne, 1995).

Misunderstanding of breakfast and food norms. Euro Disney's HR department failed on understanding the European breakfast and food norms. In this aspect, there were two problems with the food. The first one was that breakfast was not considered as something important for the Europeans, and the second one was that most of the restaurants were fast food restaurants (Keegan, 2002). For example, Disney believed that the Europeans did not eat sit-down breakfasts which resulted in Disney downsizing their restaurants before Euro Disneyland opened. Once it opened, the restaurants were bombarded with breakfast eaters. In fact, the data shows that they were trying to serve 2,500 breakfasts in a 350-seat restaurant at some of the hotels. Further, guests wanted bacon and eggs rather than just coffee and croissants (Burgoyne, 1995). In addition to the dislike of the fast food restaurants by the Europeans, the Walt Disney Company failed to realize that the Europeans were actually accustomed to eat at a set time every day. While most the Americans are usually comfortable walking around the parks with lunch in their hands, a large majority of the European guests would converge on the restaurants at 12:30 p.m. expecting to be seated for a leisurely lunch. This caused the lines to be very long. To complicate matters further, once the Europeans reached the front of the line they were told they could not have wine or beer with their lunch, as mentioned earlier. Thus, the Europeans did not have a positive "Disney experience" while eating their meals. In addition, there was not enough staff or cast members for the rush hours (Burgoyne, 1995).

Misunderstanding of vacation habits. The European's approach to vacation time and their length of visits was miscalculated by a parallel being driven with the American visits to Disney in the USA. For example, the Europeans were reluctant to take their children from school for a vacation in mid-session whereas the Americans were doing it frequently. Also, the Europeans preferred a few longer holidays rather than several short breaks. The Walt Disney Company was convinced that it would be able to "Americanize" the European habits. Unfortunately for the Walt Disney Company, this was not the case (Burgoyne, 1995).

Miscalculation of per-capita spending. Miscalculations based on insufficient marketing research were made regarding the per-capita spending of the guests at Euro Disneyland. The Walt Disney Company had assumed that guests visiting Euro Disneyland would spend large amounts of money as they did in the United States and Tokyo. More specifically, the Walt Disney Company calculated that each guest would buy $\$ 33$ worth of food and souvenirs per day. This did not happen. In fact, spending was about $12 \%$ less than predicted. European guests were going to the theme park paying the steep entry fees, but spent less per-capita on food and merchandise than the Americans. This may be due in part to the fact that many guests wanted to spend as much time on the rides as possible because of the high admission price (30\% more than Disney World in Florida) and less time shopping for souvenirs. While the American and Japanese consumers did not leave the theme parks empty handed, the Europeans did. This resulted in lower-than-expected revenue by Euro Disneyland (Burgoyne, 1995).

Miscalculation of transportation preferences. Transportation preferences of visitors to the park and around the park were also miscalculated. For example, if speaking for transportation around the park, in the initial design of Euro Disney it was assumed that the Europeans would have the same preferences as the Americans. In the USA a variety of trains, boats, and tramways carried visitors from the hotels to the park. Although it was possible to walk, most 
Americans chose to ride, while the Europeans on the other hand, chose to walk rather than ride, leaving the vehicles significantly underutilized. As for the transportation preferences to the park, it was assumed that given the automobile ownership statistics in Europe, the majority of visitors would drive their own cars to Euro Disney and that a relatively small number of visitors would arrive by bus. As a result, the parking facilities were built accordingly as were the facilities for bus drivers. It happened, however that the initial planning vastly underestimated the proportion of visitors who would arrive by bus. The facilities for bus drivers to park their buses and rest were inadequate. Euro Disney was forced to reduce the space left for parking lots and to open more space for buses and bicycles that the Europeans were more willing to use (Keegan, 2002).

Misunderstanding of French labor laws. A serious failure of the Disney's HR management was proper understanding of the differences between the US and the French labor laws. In the United States for example, given the cyclicality and seasonality of the attendance at the park, US workers were scheduled based on the day of the week and time of the year, which provided US management with high degree of flexibility and economy in staffing the park to meet high degree of visitor demand. French labor laws, however, did not provide this kind of flexibility (Keegan, 2002). In Orlando, Cast Members were accustomed to and have learned to accept being sent home if they are not needed. In Paris, however, French Cast Members felt extremely irritated following such requirements. Thus, after facing numerous problems, labor disputes and labor costs, Euro Disneyland eventually was forced to shift away from imported American working practices and towards a more French approach. This new approach set a maximum working week and annualized hourly work schedules. In addition, it reclassified jobs using the French method which allowed French citizens the ability to recognize their standard French job classifications. In fact, statistics show that as a result of the French labor laws that do not allow the level of flexibility which is possible in the USA, Euro Disney still struggles to find the right level of staffing at a theme park where the number of visitors per day in the high season can be 10 times the number in the low season (Burgoyne, 1995).

Violation of French labor law. It can also be argued that Disney's management not only lacked proper understanding of the French labor laws but also, with their activities, they were accused of violating these laws. For example, throughout training and employment, "Cast Members" (employees) were told that they must adhere to the company's strict 13 page manual of dress codes, known to Cast Members as the "Disney Look." The Europeans did not understand this "Disney Look." The "Disney Look" is a rigid code of Cast Member appearance that imposes a well-scrubbed, all-American look. It details the size of earrings to the size of finger nails to the no tolerance rule regarding facial hair and dyed hair. It was difficult for the Europeans to adhere to an "American look" since they were not American and they believed that these requirements interfered with their "individualism." Furthermore, the French were hardly specialists in service. Thus, in December 1994, Euro Disneyland was taken to French court contesting the Walt Disney Company's strict dress code, which was believed to violate French labor law. As a result, later on Euro Disneyland was forced to restructure their dress code and align it with the French dress code (Burgoyne, 1995).

Miscalculation of risk factors. Last but not least, Disney failed to conduct a proper risk evaluation and consider different scenarios for potential developments in the European market. Disney failed to see the signs of the approaching European recession. As the recession began to develop, the French real-estate market tumbled, thus, destroying Euro Disneyland's hopes of selling their assets and receiving revenues. In addition, the recession caused French and European disposable incomes to shrink, causing families to think twice about taking an expensive trip to Euro Disneyland. Furthermore, Euro Disneyland did not realize the magnitude of the impending recession and when given numerous opportunities to sign partners who would share the risk or buy the existing hotels, Disney refused. Euro Disneyland did not want to give up any of the potential revenues once the recession was over (Burgoyne, 1995).

So far, it has been demonstrated through facts of errors and the resulting consequences, how important the strategic role of HR management could be if properly aligned with a company's strategy. In this aspect, the Walt Disney Company's venture of Euro Disneyland is an excellent source of study, training, and learning for HR professionals involved in possible foreign expansion. In addition, the Euro Disney case is a perfect example of how cultural differences are in the core of a company's success in the global arena and how a combination of mistakes at first site can drive a project that has been successful in some countries to be close to a failure in others. After all, it was exactly the lack of cultural awareness, understanding of the local labor laws and efficient risk assessments from 
the side of Disney's HR management, combined with their inability to educate the management of these factors that led to the numerous complications outlined above. Here, some more emphasis should be placed on the overall cultural differences between the American and the French culture that should have been considered by the Disney HR management, and which should have been explained through proper training to the management working on the Euro Disney strategy implementation.

\section{American Versus French Culture- Key Factors For Consideration}

Nowadays, any multinational enterprise (MNE) should be aware of the cultural environment of the country where it is operating. Not surprisingly there is a saying that a company should act globally but think locally, and be culturally aware because it is the lack of cultural awareness that causes businesses to fail. The literature nowadays is full of examples of companies which have failed in one way or another to be successful in certain countries as a result of the negligence with which they regard host countries' cultures. One vivid example of such a company is Euro Disney as has been demonstrated here. As a matter of fact, Euro Disney demonstrates something very important for the HR management in any global company, i.e. cultural awareness is very important for expatriates and their managers who belong to different cultures such as Western and Asian cultures. It is also tremendously important for different Western cultures which for some might seem to be similar. Cultural differences must be considered from different angles and despite the fact they might fall under the same category, like Western culture for example, it is the cultural differences for the specific country that matter.

For example, both France and the USA are Western culture countries and at the same time they have major cultural differences. Thus, it was the lack of awareness for these cultural differences that caused the initial project of Euro Disney to fail. The project was executed as an equivalent to the American model of Disney, under the assumption that it will have the same level of success in France as it had in the United States. However, the French culture, despite being Western in nature, is quite distinct and in many aspects radically different from the American mores and norms. Speaking of the two countries, it is very important for the characteristics presented in Table 1 to be considered by expatriate and their managers, as originally outlined by Professor Gert Hofstede.

Table 1 - Western Cultural Orientations

\begin{tabular}{|c|c|c|}
\hline & $\begin{array}{l}\text { France } \\
\text { - Strong Uncertainty Avoidance } \\
\text { - Large Power Distance } \\
\text { - Feminine } \\
\text { - Individualistic }\end{array}$ & $\begin{array}{l}\text { United States } \\
\text { - Weak Uncertainty Avoidance } \\
\text { - Low Power Distance } \\
\text { - Masculine } \\
\text { - Individualistic }\end{array}$ \\
\hline
\end{tabular}

It can easily be observed that despite the fact that both the French and the USA cultures fall under the category of the Western cultures, they are radically different. This could have served as the first sign for Disney's HR management that cultural awareness training is of high importance and that a more detailed analysis of the cultural differences is essential. An interesting observation that can be made is that Japan, which is an Asian culture and quite often given as an example when cultural differences are outlined between Western and Asian cultures, has almost the same characteristics as the French culture, i.e. strong uncertainty avoidance, large power distance, and individualism. The main difference is that while the French culture is feminine in nature, the Japanese one is masculine. Considering these similarities, it is feasible for one to ask how it is possible for Disney Tokyo to be such a success when it was a reflection of the American Disney and how it is possible for Euro Disney to be a complete failure when it is in a country where the culture is much more similar to that of the United States. When speaking about different countries, the answer is that generalizations should be avoided. Each country should be considered individually and the country's culture should be carefully researched no matter if the country belongs to the Western culture or a different one.

For example, even though Japan is so culturally different in comparison to the United States, these cultural differences did not necessarily affect the success of Disney in Tokyo perhaps because during the time when Disney was built in Japan, the United States was perceived as a model of an affluent society and Japan was starting to feel part of the world culture. Tokyo Disneyland was a symbol of Japan's entry into the world economy. Another reason 
why the Tokyo Disneyland was such a success could be explained with the importance that the Asian culture places on factors such as affiliation, admiration and status (Keegan, 2002). A visit in the Tokyo Disney was regarded as something prestigious, something that was a sign of a good status in society and as a result every person or family, not willing to stay behind and to be affiliated with these characteristics, would go to the Tokyo Disney (Keegan, 2002).

Thus, despite the lack of serious modifications of Tokyo Disney and despite the cultural difference between the USA and Japan, the Disney in Tokyo was a perfect fit for the cultural needs of the Asians. However, the success there could not easily be translated into Europe. While it was a good feeling for the Asians to be associated with the American culture, the Europeans did not seek such an association. Europeans, and French in particular, are very proud of their traditions, culture, history, manners, fashion, and passion for life, and the attempt that Disney made to Americanize the French way, was taken as an insult and humiliation. As the Euro Disney case presented, almost everything that Disney initially projected for Euro Disney was the opposite of the reality in Europe and France.

\section{Lessons For International / Strategic HR Management}

The Euro Disney case is an illustration of how critical the consequences can be when a company's HR management is not aligned with a company's strategy. Cultural differences, labor laws, foreign risks - all of them are part of the HR's responsibilities. If a company's HR management is aware of the specifics in the foreign country, it will not only be able to assign the right managers for the foreign project but will also be able to train the management team and educate them about the critical elements for success in the host country. In this aspect, the following lessons could be extracted from the Euro Disney case:

1. The ethnocentric approach to management and global operations simply does not work together. Rather a company should be geocentric and adapt to any single market.

2. A success of a certain project in one or two countries is not a guarantee that the same project will be successful in another country.

3. Americans taking high management positions in domestic companies might not demonstrate the same performance success in a different country. Expatriate managers should be provided both with cultural awareness and sensitivity training. Otherwise, management positions should be given to natives of the country where the company/project will be developed.

4. Laws of different countries should be respected and taken into consideration in a project implementation. Laws that apply at home might not apply abroad.

5. Cultural sensitivity to differences determines the thin line between a company's success and failure.

6. Self-reference criterion should be suppressed as much as possible and host culture, traits, habits, and norms should be considered.

7. The norm and the formula for success for any global firm should be to think globally and act locally.

8. Differentiation rather than standardization is essential for maintaining competitiveness.

9. HR strategic management should be on the same page with a company's strategy. Strategic planning should not be regarded just as a company's objective, but a human resource imperative.

\section{Summary}

The general consensus from the study of the Euro Disney case is that a company's HR management should be aligned with a company's short- and long-term objectives if a company wants to successfully accomplish its mission and ensure a competitive advantage. In this aspect, in the contemporary business organization, HRM, instead of just being supportive, should play the role of a strategic partner in the formulation of the company's strategies, as well as, in the implementation of those strategies through relevant human resource activities such as recruiting, selecting, training, and rewarding personnel.

The provided example of Euro Disney is justification of the important role of HR as a strategic partner. It was the lack of HR strategic management that led to the numerous mistakes in the Euro Disney's project development. Lack of awareness of the French culture, the French labor laws, the business risks, and the lack of training and assigning the right personnel were all factors that contributed to the failure of Walt Disney in Europe. The moral of the story is that if a company wants to be successful in today's competitive and culturally diverse 
world, a company's decisions should be carefully aligned with a company's strategy. In this respect, if a company's HR management is aligned with a company's strategy, it holds the key to the company's success in the host country. HR professionals increase the capacity of a business to execute its strategies and to execute them well.

\section{Reflection Questions For Discussion}

Expatriate employees and their managers must strategically plan to be successful in their global expansion efforts and implementation. As such, appropriate training and development in regard to cross-cultural differences might be very useful before they embark on such a journey. Besides cultural awareness training, the program should also encourage participants to reflect on such questions as the following:

1. What is strategic human resource management? Discuss in the global context using examples.

2. What are the general staffing orientations that global companies can subscribe to as per their internal policies and organizational culture?

3. What are some of the common mistakes the Disney made when they opened Euro Disney in France?

4. What are some of the common mistakes that other firms have made in their efforts to expand internationally? Mention at least one company's efforts and the lessons that can be learned from it.

5. What can multinational corporations learn from the mistakes of global firms? Mention three mistakes that expatriate manager and leaders can and should avoid as they expand internationally into new markets and cultures.

6. Can you think of specific companies, the business practices of which had failed because of the lack of alignment between HR and business strategy, and the lack of cultural awareness?

7. In the paper, a brief comparison was provided for the French and US cultures, as well as facts were mentioned about the Japanese. If coming from a country other than those mentioned, compare your culture to that of the US, France or Japan. Mention the major differences and similarities.

8. From previous experience that you have had, can you describe a situation in which you have thought in a certain way about a foreign culture, which at the end proved wrong when visiting that culture?

9. Have you ever been in the position of an expatriate? If so, how efficient was the HR Department of your company in preparing you for a visit in the foreign country?

10. Do you think that a "Needs Assessment Training" is an efficient tool for improving expatriates' work performance? Discuss your reasons.

\section{AUTHOR INFORMATION}

Bahaudin G. Mujtaba, D.B.A., is an Associate Professor of Management and Human Resources Management at Nova Southeastern University's H. Wayne Huizenga School of Business and Entrepreneurship. Bahaudin has served as manager, trainer and management development specialist in the corporate world as well as a director, department chair and faculty member in academia. His areas of research are management, training, diversity management, and cross-cultural management.

Guergana Karadjova-Stoev is completing a Masters of International Business Administration degree at the Nova Southeastern University's the H. Wayne Huizenga School of Business and Entrepreneurship. She lives in Toronto, Canada. Her research interest includes topics in the fields of cross-cultural management, international business, and globalization.

\section{REFERENCES}

1. Burgoyne, L. (1995). Walt Disney Company's Euro Disney Venture: A Study in Corporate Foreign Expansion. Hidden Mickeys, Retrieved on July $7^{\text {th }}, 2006$ from the following URL: http://www.hiddenmickeys.org/Paris/English/LynEuroDisney.html

2. Cavico, F. \& Mujtaba, B. G., (2008). Legal Challenges for the Global Manager and Entrepreneur. Kendal Hunt Publishing Company. United States. ISBN: 978-0-7575-4037-0.

3. Chaturvedi, S. (2006). Strategic Human Resource Management. Human Links, Retrieved on July $7^{\text {th }}, 2006$ from the following URL: http://www.humanlinks.com/manres/articles/shrm.htm 
4. $\quad$ Dolezalek, H. (2008). Good Job! Training, 45(6), pp. 32-34.

5. Dowling, P. J.; Festing, M.; and Engle Sr., A. D. (2009). International Human Resource Management: Managing People in the Multinational Context $\left(5^{\text {th }}\right.$ ed.). Thomson / South-Western Publishing.

6. Hofstede, Gerte. (2006). Retrieved March 30, 2006, from http://en.wikipedia.org/wiki/Hofstede

7. Hofstede, G. (1980). Culture's consequences: International differences in work-related values. Beverly Hills, CA: Sage Publications.

8. Keegan, W. (2002). Euro Disney Case (A). Global Marketing Management, $7^{\text {th }}$ edition, Prentice Hall, New Jersey, USA

9. $\quad$ Mead, R. (2005). International Management: Cross-Cultural Dimensions, $3^{\text {rd }}$ Edition. Blackwell Publishing, United States.

10. Mendenhall, Mark E.; Oddou, Gary R.; and Stahl, Gunter K. (2007). Readings and Cases is International Human Resource Management $-4^{\text {th }}$ ed. Routledge Publishers, Taylor \& Francis Books.

11. Mujtaba, B. G. (2007a). Cross Cultural Management and Negotiation Practices. ILEAD Academy Publications; Florida, United States. ISBN: 978-0-9774211-2-1.

12. Mujtaba, B. G. (2007b). Workpalce Diversity Management: Challenges, Competencies and Strategies. ISBN: 1-59526-548-1. Llumina Press; Phone: 866-229-9244 or: 954-726-0902). Website: http://www.llumina.com/store/workforcediversitymanagement.htm

13. Mujtaba, B. G. (2006). Cross Cultural Change Management. ISBN: 1-59526-568-6. Llumina Press, Tamarac, Florida.

14. OPM - U.S. Office of Personnel Management (1999). Strategic HR Management: Aligning with the Mission. Retrieved on July $7^{\text {th }}$, 2006 from the following URL: http://www.opm.gov/studies/alignnet.pdf

15. Price, A. (2000). Human Resource Practices at Disney, HRM Guide. Retrieved on July $7^{\text {th }}, 2006$ from the following URL: http://www.hrmguide.net/hrm/Disney.htm

16. Thompkins, J. (2002). Strategic Human Resources Management in Government: Unresolved Issues. Pubic Personnel Management, 31(1), pp. 95-110. 